NIST Economic Analysis Briefs 5

\title{
The Economic Impact of Technology Infrastructure for Advanced Roll-to-Roll Manufacturing
}

\author{
Gary Anderson (gary.anderson@nist.gov) \\ Technology Partnerships Office, Innovation \& Industry Services
}

October 2016

\section{Key Findings}

- Conservative estimates indicate that meeting technology infrastructure needs would lower advanced roll-to-roll production costs by $15 \%$ saving domestic manufacturers over \$353 million annually.

- Barriers to innovation increase the cost of roll-to-roll manufacturing R\&D, weaken private investment incentives, and magnify the role of public institutions.

- Overcoming critical technical barriers may require investments in public-private manufacturing consortia.

\section{Introduction}

Advanced roll-to-roll (R2R) production methods offer the opportunity to merge the precision and uniformity of the microelectronics industry with the scale and cost structure of high throughput industries such as optical films, printing and textiles. A recent study ${ }^{1}$ commissioned by the National Institute of Standards and Technology (NIST) finds "new, emerging industries are taking advantage of the ability to generate high-fidelity patterned structures in a continuous, R2R additive process." However, "further development and widespread adoption of this manufacturing technology will require resolving key technical challenges in standards, metrology, and manufacturing technology platforms." This technology infrastructure ${ }^{2}$ is the broad base of public and quasi-public technologies and technical knowledge that support the research, development, production and diffusion activities of national laboratories, universities and firms alike. The study finds that developing the technology infrastructure to meet these needs "would unlock significant economic value by lowering scrap rates, improving yields, and improving R\&D and manufacturing efficiency. Increased quality and reliability combined with improved processes would expand existing product lines and allow the industry to move into new markets."

The unique contribution of this analysis is the focus on technology infrastructure, "a nuanced yet critically important issue in manufacturing technology development." The results are based on in-depth interviews with 45 experts as well as an extensive analysis of prior research. Primary data collection drew from the entire R2R value chain:

NLا 
developers of R2R manufacturing technologies; system integrators and consultants; end users within the manufacturing sector; industry associations; universities; and research centers. The study collected data from end users in optical films, flexible electronics, biomedical applications, energy technologies, and environmental technologies. Based on this analysis, the study identified critical gaps in technology infrastructure in eight areas (See Table 1). Further, the study estimates that meeting these technology infrastructure needs would save $15 \%$ of production costs in the R2R manufacturing sector. Conservatively, this will save manufacturers $\$ 353$ million annually.

The needs include standards and measurement for inks and substrates, metrology and tooling for real-time feedback, technology for alignment and registration on a moving substrate, process modeling and controls, standard terminology, nanoscale seam-free tooling, and new materials and substrates. The analysis indicates meeting industry needs for real-time metrology would save manufacturers $\$ 89.5$ million annually. New materials for inks and substrates as well as standards for these inputs would save manufactures over $\$ 100$ million. The results show that process modeling, terminology and packaging would yield lower annual benefits.

\section{Table 1: Technology Infrastructure Gaps and Potential Benefits}

\begin{tabular}{|c|c|}
\hline Infrastructure Need & Technologies \\
\hline \multirow{2}{*}{$\begin{array}{l}\text { Standards and measurement technology } \\
\text { for input materials }\end{array}$} & Reference materials and quality standards \\
\hline & $\begin{array}{l}\text { Standard protocols and best practices to improve repeatability and materials quality } \\
\text { validation }\end{array}$ \\
\hline \multirow[t]{4}{*}{$\begin{array}{l}\text { Metrology for tooling and real-time } \\
\text { feedback }\end{array}$} & $\begin{array}{l}\text { Advanced analytical tools and sensors for probing a moving surface and metrology } \\
\text { that extends beyond optical resolution }\end{array}$ \\
\hline & Large-area metrology \\
\hline & $\begin{array}{l}\text { Metrology for obtaining measurement on a moving, reflective, and/or optically } \\
\text { transparent web }\end{array}$ \\
\hline & $\begin{array}{l}\text { In-line flexible-substrate metrology for mechanical reliability, thermal effects, } \\
\text { positional accuracy and reliability across a wide surface, processing on a fast-moving } \\
\text { web }\end{array}$ \\
\hline $\begin{array}{l}\text { Technology for alignment and } \\
\text { registration on a moving substrate }\end{array}$ & Technology to enable high throughput alignment \\
\hline \multirow[t]{3}{*}{ Process modeling and controls } & Process control (move to closed loop, develop and integrate sensors) \\
\hline & Automated design flows \\
\hline & Process simulation tools \\
\hline Terminology & Consistent international standards for nomenclature \\
\hline \multirow{2}{*}{$\begin{array}{l}\text { Tooling for seam-free fabrication, } \\
\text { including cylindrical masters that are } \\
\text { seamless and have nanoscale fidelity }\end{array}$} & $\begin{array}{l}\text { Removing the barriers that impede product size or length, thereby expanding } \\
\text { product portfolios }\end{array}$ \\
\hline & $\begin{array}{l}\text { Removing the need to create molds from masters, which would greatly lower } \\
\text { turnaround times, decrease wastage, and greatly decrease cost of goods }\end{array}$ \\
\hline New materials and substrates & New materials formulations, especially for high-conductivity applications \\
\hline
\end{tabular}


Figure1: Total Annual Impact, Apportioned by Technology Need (Millions of 2013 US\$)

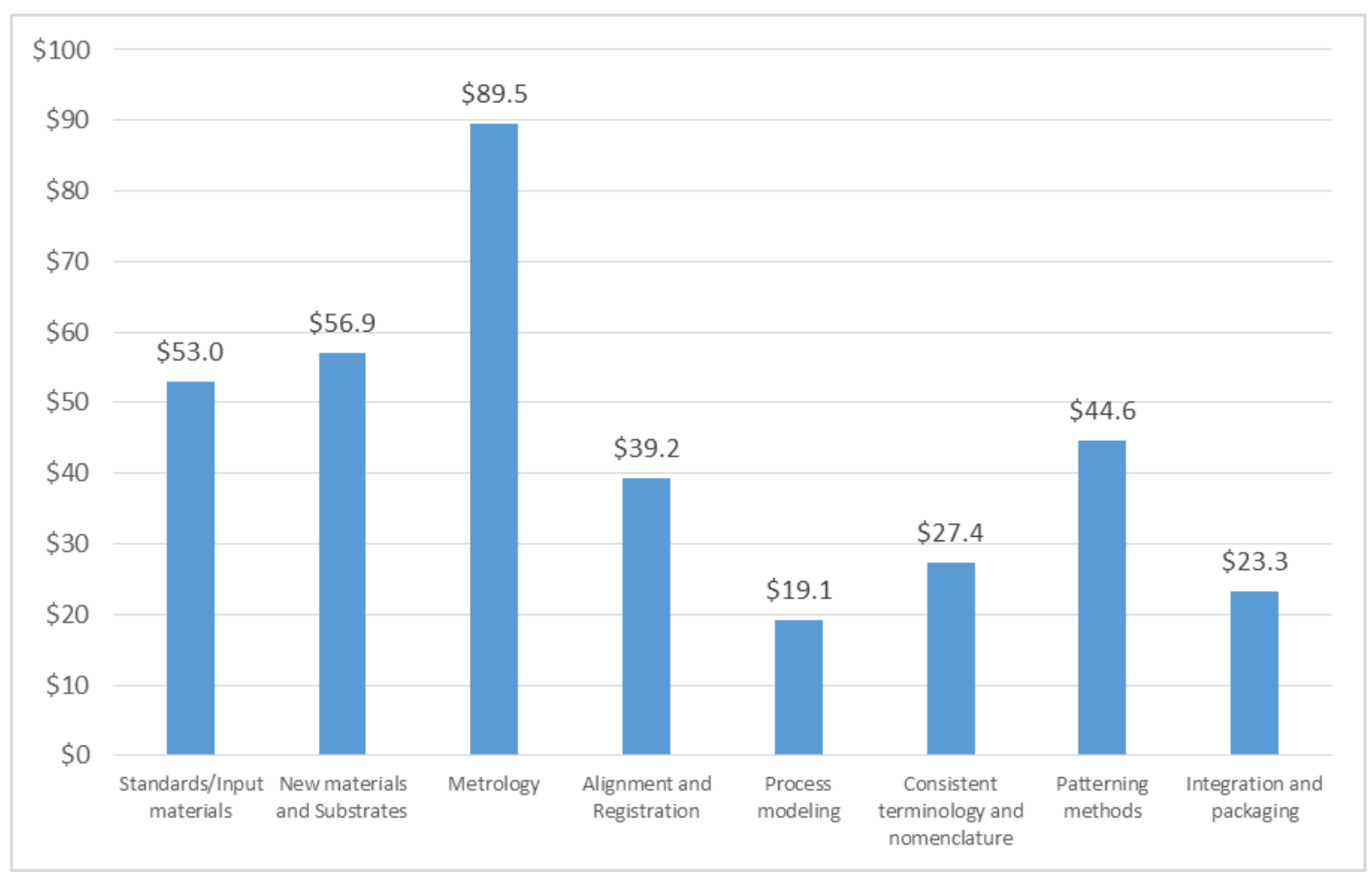

\section{Key Findings}

First, the results indicated that meeting industry needs for R2R technology infrastructure would lower R2R manufacturing production costs by $15 \%$. This rate of cost reduction is 3 to 5 times higher than other recently completed NIST advanced manufacturing studies. ${ }^{3}$ Overall, the $\$ 353$ million in total annual cost savings is impressive, for several reasons. First, due to the conservative approach taken in this study, the total impact measure depends critically on the current market size, which is small. Further, many speculative and difficult to quantify impacts such as research costs savings, accelerated market entry, increased product quality and reliability benefits, market expansion, long-term competitiveness, and other societal benefits are excluded from the estimate. While respondents reported that providing the identified technical infrastructure would "de-risk the application of R2R manufacturing technologies and encourage, or 'crowd in,' further investment by the private sector," such benefits were not quantified. Because meeting the identified technical needs will likely increase advance R2R adoption and promote these long term benefits, the benefits quantified here are likely underestimates of the full impact of meeting these technical infrastructure needs. 
The study identifies distinct barriers to innovation, caused by market failures, ${ }^{4}$ beyond the public good nature of technology infrastructure, that create further inefficiencies and magnify the role of public institutions in meeting these scientific and technical needs. The gaps alongside critical uncertainties increase the cost of advanced R2R research, development and deployment. Just as an R2R end user cannot easily verify the quality of the inks and substrates, they cannot verify the quality of proprietary data and testing developed by ink and substrate suppliers. The data collected in this study showed "firms are spending money duplicating one another's efforts to address strikingly similar challenges: validating input materials quality, building reference databases, sorting out alignment and registration on moving substrates, and developing real-time metrology and process modeling software and tools." In this environment, publicly available and trusted third-party data can lower research and adoption costs and increase the incentive to invest in new technology. Absent critical materials property data for inks and substrates, process control metrology and other critical standards, advanced R2R research, development and deployment is excessively costly and the incentives for private investment in $\mathrm{R} 2 \mathrm{R}$ research will continue to be low.

Finally, in addition to critical measurement and standards needs, this study identifies a number of critical technology platforms such as new inks, substrates, process models, and other technology platforms. At times, these technical barriers are substantial. The study reported that "precision and speed are never going to go together until huge revolutions are made." The study finds that ensuring technology platforms are developed that meet industry needs may require investments in public-private manufacturing consortia.

\section{References}

[1] Anderson G (2013) The Impact of Federally Performed R\&D: Twenty Years of Economic Analysis at the National Institute of Standards and Technology. 2013 Technology Transfer Society Conference.

[2] Anderson G (2016) The Economic Impact of Technology Infrastructure for Advanced Manufacturing: An Overview. (NIST, Gaithersburg, MD) NIST Economic Analysis Briefs 1.

[3] Link A Scott J (2011) The theory and practice of public-sector R\&D economic impact analysis. (NIST, Gaithersburg, MD) Planning Report 11-1. https://www.nist.gov/sites/default/files/documents/director/planning/report11-1.pdf.

[4] O'Connor AC, Beaulieu TJ, Rothrock GD (2016). Economic Analysis of Technology Infrastructure Needs for Roll-to-Roll Manufacturing. (NIST, Gaithersburg, MD) NIST GCR 16-008.

[5] Tassey G (2007) The Technology Imperative. (Edward Elgar, Cheltenham).

[6] Tassey G (2015) The Economic Nature of Knowledge Embodied in Standards for TechnologyBased Industries. Routledge Handbook of the Economics of Knowledge, eds Antonelli C, Link A (Routledge, New York), pp. 189-207.

\footnotetext{
${ }^{1}$ See O'Connor et al [4].
} 
${ }^{2}$ Technology infrastructure includes infratechnologies and technology platforms. Infratechnologies are technical tools, such as measurement and test methods, reference materials, scientific and engineering databases, process models, and the technical basis for physical and functional interfaces between individual components of both cyber and physical systems technologies. Technology platforms are precompetitive proofs of concept that demonstrate the potential commercial viability of multiple new or improved products, processes, or services. Technology infrastructure shares many common feature with tangible infrastructure. Namely, it is difficult and even undesirable to exclude potential users implementing the technology and usage of the technology infrastructure by a particular organization does not does not preclude others from benefiting to much the same extent. See Anderson [1], Link and Scott [3] and Tassey [5] for a richer discussion of the public good nature of technology infrastructure.

${ }^{3}$ See Anderson [2] for an overview.

${ }^{4} \mathrm{~A}$ market failure is a situation where free markets do not allocate resources efficiently. In particular, the study finds evidence that network externalities, high technical risk, uncertainty and asymmetric information, and economies of scope all impact research in technology infrastructure for R2R. The result is that markets invest too few resources in R\&D. 